[20] Cleland, J. G. F., Bunting, K. V., Flather, M. D., Altman, D. G., Holmes, J. et. al. (2017). Beta-blockers for heart failure with reduced, mid-range, and preserved ejection fraction: an individual patient-level analysis of double-blind randomized trials. European Heart Journal, 39 (1), 26-35. doi: http://doi.org/10.1093/eurheartj/ehx564

[21] Lund, L. H., Claggett, B., Liu, J., Lam, C. S., Jhund, P. S., Rosano, G. M. et. al. (2018). Heart failure with mid-range ejection fraction in CHARM: characteristics, outcomes and effect of candesartan across the entire ejection fraction spectrum. European Journal of Heart Failure, 20 (8), 1230-1239. doi: http://doi.org/10.1002/ejhf.1149

[22] January, C. T., Wann, L. S., Alpert, J. S., Calkins, H., Cigarroa, J. E., Cleveland, J. C. et. al. (2014). 2014 AHA/ACC/HRS Guideline for the Management of Patients With Atrial Fibrillation: Executive Summary. Circulation, 130 (23), $2071-2104$. doi: http://doi.org/10.1161/cir.0000000000000040

\title{
ST2 PLASMA LEVEL IN PATIENTS WITH ACUTE MYOCARDIAL INFARCTION WITHOUT ST ELEVATION AND DIFFERENT CLINICAL CHARACTERISTICS
}

\author{
Iryna Mezhiievska \\ irinamezhiievska@gmail.com \\ Valerii Ivanov ${ }^{1}$ \\ Valentyn Maslovskyi ${ }^{1}$ \\ ${ }^{1}$ Department of Internal Medicine No. 3 \\ National Pirogov Memorial Medical University \\ 56 Pirogova str., Vinnytsya, Ukraine, 21018
}

\begin{abstract}
The aim. Estimation of ST2 plasma level in patients with acute myocardial infarction without ST elevation (NSTEMI) and its relationship with different clinical characteristics.

Materials and methods. 165 patients aged from 35 to 79 (average of $60.7 \pm 0.8$ years) with various forms of coronary artery disease (CAD) with and without arterial hypertension were examined. The variability of plasma ST2 level in different forms of CAD and in NSTEMI group was analyzed depending on gender-age and clinical characteristics and features of the disease course.

\section{Results:}

The results of the present investigation were that the ST2 level in the main cohort was in range from 5.5 to 233.9 (in the middle $-49.8 \pm 3.5 \mathrm{ng} / \mathrm{ml}$ (median indicator -34.7 and the interquartile range -21.9 and 59.1 respectively).

Significantly higher ST2 levels were found in patients with NSTEMI, unlike the comparison group, in the median analysis ( 35.9 vs. $27.7 \mathrm{ng} / \mathrm{ml}, \mathrm{p}=0.047$ ) and no statistical differences were observed in the mean values.

In patients with NSTEMI, a certain association of ST2 level in plasma with the MI course was detected. A higher level of neurohormone is registered with anterior unlike posterior ECG localization of MI; at high unlike moderate risk on the GRACE scale; when complicated unlike the uncomplicated course of MI; in the case of acute HF and cardiac arrhythmias unlike patients with the absence of these manifestations in the acute period of MI.

Conclusions. High variability of ST2 level in plasma was demonstrated in patients with NSTEMI on the first day after destabilization (minimum and maximum values -12.7 and 233.9 respectively, median - 35.9 and interquartile range $-25.9 \mathrm{and} 55.7 \mathrm{ng} / \mathrm{ml}$ ).

It is shown that significantly higher ST2 level in plasma is determined in patients with acute MI regardless of its variant among different clinical forms of CAD.

It is found that significantly higher level of ST2 in patients with NSTEMI is recorded in the case of concomitant HTN and type 2 diabetes, with smoking and heavy cardiovascular heredity. Proved influence of the character of MI course on the level of ST2
\end{abstract}




\section{Introduction}

The analysis of the health dynamics status among Ukrainian population in recent years shows a negative trend, namely the deterioration of life quality and patients life expectancy [1, 2]. An indisputable leader in this process is coronary artery disease (CAD) and especially its acute forms, which are associated with high mortality [3, 4]. On this basis, the study of different aspects of this problem is of great interest for the practical health care of Ukraine.

Among the acute forms of CAD, NSTEMI is associated with extremely unanticipated course and unfavorable prognosis in the near and distant period [4]. Therefore, the development of NSTEMI stratification and prognosis is in the focus of scientific society. In this sense, various non-invasive biomarkers, such as troponin I (TnI), natriuretic peptide (BNP and NT-proBNP), galectin-3, growth factor-expressing gene 2 (ST2) and others, have been recently studied in detail [5]. Among the latter, a great deal of attention is paid to ST2 [6].

ST2 as a neurohumoral factor attracted attention due to already available scientific data on its unique properties and a fairly wide range of pathophysiological effects and a potential role in the diagnosis and prognosis of asymptomatic and symptomatic structural remodelling and fibrosis of myocardium and myocardial dysfunction $[7,8]$. The diagnostic value of the biomarker has been demonstrated in both acute coronary syndromes and chronic stable heart failure [9, 10]. ST2 has proven to be a highly informative marker in predicting left ventricular remodeling and monitoring positive treatment response in patients with systolic heart failure (HF), exceeding the sensitivity of factors such as NT-proBNP, highly sensitive cardiac troponin T and galectin-3 [11, 12].

Thus, the modern scientific sources analysis demonstrates the prospect of using ST2 level in plasma as a diagnostic marker that reflects the presence and severity of structural remodelling of myocardium in various cardiovascular pathologies, including MI [13, 14].

The aim of the study was to evaluate ST2 level in plasma among the patients with NSTEMI and its relationship according to different clinical characteristics.

\section{Materials and methods}

All studies conform to the principles of the Declaration of Helsinki of the World Medical Association. The study protocol, the form of informed consent of patients and other documents related to the study were approved at the meeting of the Academic Council of the National Pirogov Memorial Medical University, Vinnytsya (excerpt from the protocol No. 2 from 28.11.2017). Informed consent to participate in the study was discussed and signed by all study participants.

The study is based on the results of a comprehensive examination of 165 patients aged 35 to 79 (average $60.7 \pm 0.8$ ) years with various forms of CAD with and without arterial hypertension (HTN). Among the surveyed 114 (69.1\%) patients were male and 51 (30.9\%) were female respectively. The ratio of men to women was 2.2 to 1.0 , indicating a significant predominance in the study of male patients $(\mathrm{p}<0.0001)$.

At the time of their inclusion in the study, all patients were hospitalized in the cardiology department for infarction patients of the Vinnytsya Regional Clinical Medical Diagnostic Center for Cardiovascular Pathology for 2016-2018 years.

The criteria for patient inclusion in the study were: different forms of CAD (NSTEMI, STEMI, NSTE-ACS, chronic coronary syndromes) and patients age from 30 to 80 years. The exclusion criteria were:

1) past and repeated acute myocardial infarction;

2) the age of patients under 30 and over 80 ;

3) HF NYHA III-IV at the time of the study inclusion; 
4) diseases of the respiratory system, kidneys and liver, which were accompanied by signs of pulmonary, renal and hepatic failure; anemic conditions with haemoglobin levels below $110 \mathrm{~g} / \mathrm{l}$;

5) presence of rheumatic and congenital heart defects, idiopathic and inflammatory myocardial lesions;

6) malignancies, severe neuropsychiatric disorders, alcohol abuse.

The main clinical trial was presented to 90 patients with NSTEMI aged 38 to 79 (mean $61.3 \pm 1.1)$ years. Among them, 60 (66.7\%) patients were male and 30 (33.3\%) were female respectively. The ratio of men to women was 2.0 to $1.0(\mathrm{p}<0.0001)$. It was noted that in the main clinical group, as well as in the general cohort of patients, men predominated significantly. Time from the moment of destabilization to hospitalization in the hospital ranged from 1 to 24 and averaged $10.6 \pm 1.0$ hours. In the vast majority $(87.8 \%$ ) of patients with NSTEMI according to the ECG recorded anterior localization of MI (in $87.8 \%$ - depression of ST-segment from 2 to $5 \mathrm{~mm}$ and in $12.2 \%$ - T-wave inversion from 2 to $6 \mathrm{~mm}$ in two or more leads) and an increase in plasma troponin levels compared to the reference rate of 2.5 to $18.4 \mathrm{ng} / \mathrm{ml}(7.5 \pm 0.5 \mathrm{ng} / \mathrm{ml}$ on average).

As groups of comparison were formed 3 groups with other different clinical forms of CAD. Thus, group 1 consisted of 25 patients with verified chronic coronary syndromes (CCS) (mean age $-60.6 \pm 2.4$ years, men $-68.0 \%$ and women $-32.0 \%$ respectively); group $2-25$ patients with NSTE-ACS (mean age $-61.4 \pm 2.4$ years, males $-68.0 \%$ and females $-32.0 \%$, respectively) and 3rd - 25 patients with STEMI (mean age 58.3 \pm 2.3 years, males $80.0 \%$ and females $20.0 \%$, respectively). In patients with STEMI, unlike the main group, there was a significantly shorter mean period from the destabilization onset to hospitalization $(6.3$ vs. $10.6 \mathrm{~h}, \mathrm{p}<0.001)$ and the incidence of anterior MI localization (64.9\% vs. $87.8 \%, \mathrm{p}=0.006)$ and a higher mean troponin level (10.4 vs. $7.5 \mathrm{ng} / \mathrm{ml}, \mathrm{p}=0.003$ ) which was logical.

The majority of the surveyed had concomitant HTN, the incidence of which was $84.4 \%$ $(n=76)$ in the main group and $85.3 \%(n=64)$ in the comparison groups. Most patients had observed Crade II (32.9 \% and $46.1 \%, \mathrm{n}=30$ and 36$)$ and Crade III of HTN (40.6 \% and $35.9 \%, \mathrm{n}=37$ and 27 respectively). Such risk factor as smoking was determined in almost half of the surveyed - in $45.6 \%(n=41)$ of patients in the primary and in $58.7 \%(n=44)$ - comparison groups respectively. In almost one third of patients, abdominal obesity of Grade I-II (BMI $>30 \mathrm{~kg} / \mathrm{m} 2)$ was determined in $32.2 \%(\mathrm{n}=29)$ of the primary and $42.7 \%(\mathrm{n}=32)$ of the comparison groups respectively. $11.1 \%$ $(\mathrm{n}=10)$ and $14.7 \%(\mathrm{n}=11)$ of patients were diagnosed with type 2 diabetes mellitus and $50.0 \%$ $(n=45)$ and $42.7 \%(n=32)$, respectively with impaired heredity in cardiovascular disease.

Laboratory study of the plasma ST2 levels was performed by enzyme-linked immunosorbent assay in all patients on the first day of hospitalization before hospital coronary and ventriculography (CVG). Presage ${ }^{\circledR}$ ST2 Assay EIA Test Kits No. BC-1065E and BC-1066E manufactured by CRITICAL DIAGNOSTICS 3030 Bunker Hill St. Suite 117A San Diego, CA 92109 were used to determine ST2.

The difference between the main clinical group and the comparison group, the gender difference and the difference of ST2 level depending on different clinical characteristics were calculated using nonparametric statistical methods (Mann-Whitney test). The statistical significance of the difference between the measured parameters among the CAD groups was calculated by Kruskal-Wallis ANOVA \& Median test.

\section{Results}

The results of the present investigation were that the ST2 level in the main cohort was in range from 5.5 to 233.9 (in the middle $-49.8 \pm 3.5 \mathrm{ng} / \mathrm{ml}$ (median indicator - 34.7 and the inter-quartile range -21.9 and 59.1 respectively). Tables 1-2 show indicators of statistics, which characterize the variability of ST2 level in small groups of illnesses.

Noteworthy significantly higher ST2 level in patients with NSTEMI, unlike the comparison group, in the analysis of medians (35.9 vs. $27.7 \mathrm{ng} / \mathrm{ml}, \mathrm{p}=0.047)$ and no statistical differences in the mean values. The latter index clearly argues, in the case of high variability of indicators in groups, the need to use nonparametric methods of comparison (the table compares the median of the indicator according to Mann-Whitney U test). 
Table 1

ST2 variation in plasma in the main clinical and comparison groups

\begin{tabular}{ccccc}
\hline \multirow{2}{*}{ Groups } & Patients & \multicolumn{3}{c}{ Variational statistics indicators } \\
\cline { 3 - 5 } & number & Min-Max (ng/ml) & $\begin{array}{c}\text { Mean } \pm \text { Standard error } \\
\text { (ng/ml) }\end{array}$ & $\begin{array}{c}\text { Median } \\
\mathbf{( 2 5} \text { and 75 Percentile) (ng/ml) }\end{array}$ \\
\hline $\begin{array}{c}\text { Patients with NSTEMI } \\
\text { Patients with other forms of } \\
\text { CAD }\end{array}$ & 90 & $12.7-233.9$ & $50.3 \pm 4.5$ & $35.9(25.9 ; 55.7)$ \\
& 75 & $5.5-200.4$ & $46.2 \pm 5.3$ & $27.7(18.4 ; 68.9)$
\end{tabular}

Mann-Whitney U test: $\mathbf{p}=\mathbf{0 . 0 4 7}$

Note: NSTEMI - non-ST elevation myocardial infarction

Table 2

ST2 variations in patients with various forms of CAD

\begin{tabular}{|c|c|c|c|c|}
\hline \multirow[b]{2}{*}{ Groups } & \multirow[b]{2}{*}{ Patients number } & \multicolumn{3}{|c|}{ Variational statistics indicators } \\
\hline & & Min-Max (ng/ml) & $\begin{array}{c}\text { Mean } \pm \text { Standard error } \\
(\mathrm{ng} / \mathrm{ml})\end{array}$ & $\begin{array}{c}\text { Median } \\
\text { (25 and } 75 \text { Percentile) } \\
(\mathrm{ng} / \mathrm{ml})\end{array}$ \\
\hline 1. NSTEMI & 90 & $12.7-233.9$ & $50.3 \pm 4.5$ & $35.9(25.9 ; 55.7)$ \\
\hline 2. NSTE-ACS & 25 & $10.9-180.2$ & $41.4 \pm 8.9$ & $24.1(17.1 ; 31.2)$ \\
\hline 3. STEMI & 25 & $12.5-200.4$ & $56.3 \pm 10.1$ & $36.1(21.6 ; 77.3)$ \\
\hline 4. CCS & 25 & $5.5-158.4$ & $39.8 \pm 8.8$ & $23.4(15.1 ; 48.9)$ \\
\hline \multicolumn{5}{|c|}{ Intergroup analysis of ST2 level by Kruskal-Wallis ANOVA \& Median test } \\
\hline Group & 1 & 2 & 3 & 4 \\
\hline 1 & & 0.02 & 1.00 & 0.01 \\
\hline 2 & 0.02 & & 0.04 & 0.73 \\
\hline 3 & 1.00 & 0.04 & & 0.03 \\
\hline 4 & 0.01 & 0.73 & 0.03 & \\
\hline
\end{tabular}

In turn, the comparison of ST2 levels in patients with various forms of CAD (Table 2) showed significant differences between groups with acute MI (1 and 3 groups) and patients with NSTE-ACS and CCS (2 and 4 groups) - 35.9 and 36.1 against 24.1 and $23.4 \mathrm{ng} / \mathrm{ml}, \mathrm{p}<0.05$ in the absence of significant differences between patients with different types of MI (35.9 and $36.1 \mathrm{ng} / \mathrm{ml}$, $\mathrm{p}=1.00$ ). Therefore, it should be thought that a significantly higher level of ST2 is present in patients with acute MI, regardless of its variant compared with patients with CCS and NSTE-ACS.

The results of ST2 analysis in the main clinical group in gender and age (Table 3 ) did not show significant differences in biomarker's levels in women and men $(\mathrm{p}=0.38)$, as well as patients of different age criteria $(\mathrm{p}=0.94)$.

Table 3

Plasma ST2 levels in patients with NSTEMI by sex and age

\begin{tabular}{cccc}
\hline Group & Patients number & $\begin{array}{c}\text { Mean } \pm \text { Standard error } \\
\text { (ng/ml) }\end{array}$ & $\begin{array}{c}\text { Median } \\
\text { (25 and 75 Percentile) (ng/ml) }\end{array}$ \\
Male & 60 & $50.1 \pm 5.0$ & $36.9(28.6 ; 56.6)$ \\
Female & 30 & $50.7 \pm 9.3$ & $34.1(22.2 ; 53.9)$ \\
Mann-Whitney U test: $\mathrm{p}=0,38$ & & & $35.4(25.9 ; 59.1)$ \\
up to 60 years & 39 & $56.1 \pm 8.9$ & $36.9(27.4 ; 55.3)$ \\
60 years and older & 51 & $46.1 \pm 4.5$ &
\end{tabular}

Mann-Whitney U test: $p=0,94$ 
ST2 level analysis in plasma depending on different clinical characteristics (Table 4) showed significant higher hormone levels in patients with concomitant HTN (39.9 vs. $31.2 \mathrm{ng} / \mathrm{ml}$, $\mathrm{p}=0.04)$ and type 2 diabetes $(68.5 \mathrm{vs} .35 .5 \mathrm{ng} / \mathrm{ml}, \mathrm{p}=0.04)$, in the presence of such a risk factor as smoking (39.6 vs. $32.7 \mathrm{ng} / \mathrm{ml}, \mathrm{p}=0.03)$ and impaired cardiovascular heredity (41.8 vs. $32.6 \mathrm{ng} / \mathrm{ml}$, $\mathrm{p}=0.01$ ). Therefore, based on the data obtained, it should be noted that in patients with NSTEMI, the ST2 level in plasma, in a certain way, depends on the presence of concomitant diseases such as HTN and type 2 diabetes, risk factors such as smoking and impaired hereditary cardiovascular pathology. The highest ST2 level was observed in patients with concomitant type 2 diabetes mellitus $(68.5 \mathrm{ng} / \mathrm{ml})$. The latter confirms the already known fact that type 2 diabetes is considered to be the most powerful factor in the development of myocardial dysfunction and HF in patients with MI.

Table 4

Plasma ST2 levels in patients with NSTEMI depending on different clinical characteristics

\begin{tabular}{cccc}
\hline Group & Patients number & $\begin{array}{c}\text { Mean } \pm \text { Standard error } \\
(\mathbf{n g} / \mathbf{m l})\end{array}$ & $\begin{array}{c}\text { Median } \\
\text { (25 and 75 Percentile) (ng/ml) }\end{array}$ \\
\hline MI & 52 & $55.8 \pm 7.2$ & $36.7(28.2 ; 57.9)$ \\
Absent & 38 & $43.2 \pm 4.5$ & $35.0(25.9 ; 52.1)$ \\
Mann-Whitney U test: $\mathbf{p}=0.47$ & & & $39.9(25.9 ; 56.1)$ \\
Concomitant HTN & 76 & $50.8 \pm 5.2$ & $31.2(20.8 ; 41.4)$ \\
Absent & 14 & $47.7 \pm 8.4$ & $39.6(28.6 ; 59.1)$ \\
Mann-Whitney U test: $\mathbf{p}=\mathbf{0 . 0 4}$ & & & $32.7(23.6 ; 50.8)$ \\
Smoking & 41 & $53.2 \pm 6.1$ & $41.8(30.6 ; 73.3)$ \\
Absent & 49 & $48.1 \pm 6.6$ & $32.6(22.4 ; 46.1)$ \\
Mann-Whitney U test: $\mathbf{p}=\mathbf{0 . 0 3}$ & & & $60.6 \pm 7.6$ \\
Burdened heredity in cardio- \\
vascular morbidity \\
Absent
\end{tabular}

Mann-Whitney U test: $\mathbf{p}=\mathbf{0 . 0 0 3}$

In turn, analysis of ST2 level depending on MI nature (Table 5) showed that a significantly higher level of neurohormone was determined at anterior localization of MI according to the ECG (37.9 vs. $29.4 \mathrm{ng} / \mathrm{ml}, \mathrm{p}=0.03)$, in the case of high risk on the GRACE scale $(\geq 140$ points) (42.0 vs. $30.3 \mathrm{ng} / \mathrm{ml}, \mathrm{p}=0.01$ ) and complicated course of MI (40.7 vs. $31.9 \mathrm{ng} / \mathrm{ml}, \mathrm{p}=0.03$ ). The complicated course of NSTEMI was registered by us in $22(24.4 \%)$ patients. Of these, 15 (16.7 \%) observed acute cardiac arrhythmias, 3 (3.3\%) had cardiac conduction abnormalities, and 4 (4.4\%) had acute HF, which was consistent with Killip III. Of the acute cardiac arrhythmias, almost half $(53.3 \%, \mathrm{n}=48)$ of patients reported frequent ventricular extrasystole with episodes of unstable ventricular tachycardia, $20.0 \%(\mathrm{n}=18)$ had attacks of persistent ventricular monomorphic tachycardia and $26.7 \%(\mathrm{n}=24)$ had paroxysmal atrial fibrillation. From $3(3.3 \%)$ of patients with acute conductivity disorders, in $2(66.7 \%)$ cases reported intermittent atrio-ventricular block of II-III degree and in 1 case $(33.3 \%)$ - sino-atrial block of II degree. 
Table 5

ST2 levels in patients with NSTEMI depending on MI course

\begin{tabular}{|c|c|c|c|}
\hline MI course characteristics & Patients number & Mean \pm Standard error $(\mathrm{ng} / \mathrm{ml})$ & $\begin{array}{c}\text { Median } \\
(25 \text { and } 75 \text { Percentile) }(\mathrm{ng} / \mathrm{ml})\end{array}$ \\
\hline Frontal localization of MI & 79 & $53.5 \pm 5.4$ & $37.9(29.6 ; 58.9)$ \\
\hline Rear localization of MI & 11 & $38.1 \pm 5.0$ & $29.4(23.2 ; 47.9)$ \\
\hline \multicolumn{4}{|l|}{ Mann-Whitney U test: $\mathbf{p}=\mathbf{0 , 0 3}$} \\
\hline $\begin{array}{c}\text { High risk ( } \geq 140 \text { points) by } \\
\text { Grace }\end{array}$ & 36 & $46.1 \pm 5.7$ & $42.0(30.8 ; 64.1)$ \\
\hline $\begin{array}{l}\text { Low and moderate } \\
(<140 \text { points }) \text { by Grace }\end{array}$ & 54 & $33.3 \pm 6.7$ & $30.3(21.8 ; 55.2)$ \\
\hline \multicolumn{4}{|l|}{ Mann-Whitney U test: $\mathbf{p}=\mathbf{0 , 0 1}$} \\
\hline Uncomplicated course & 68 & $42.8 \pm 5.5$ & $31.9(25.2 ; 46.4)$ \\
\hline Complicated course & 22 & $49.2 \pm 8.0$ & $40.7(32.9 ; 61.5)$ \\
\hline \multicolumn{4}{|l|}{ Mann-Whitney U test: $\mathbf{p}=\mathbf{0 , 0 3}$} \\
\hline Acute heart rate disorders & 15 & $62.7 \pm 15.1$ & $47.1(31.2 ; 87.5)$ \\
\hline Absent & 75 & $47.8 \pm 4.5$ & $35.6(25.7 ; 55.3)$ \\
\hline \multicolumn{4}{|l|}{ Mann-Whitney U test: $\mathbf{p}=\mathbf{0 , 0 0 4}$} \\
\hline Conduction abnormalities & 3 & $72.3 \pm 28.3$ & $43.7(38.2 ; 57.9)$ \\
\hline Absent & 87 & $49.0 \pm 4.5$ & $35.2(25.7 ; 55.3)$ \\
\hline \multicolumn{4}{|l|}{ Mann-Whitney U test: $p=0,13$} \\
\hline Acute HF (Killip III) & 4 & $57.0 \pm 7.4$ & $56.3(35.4 ; 103.9)$ \\
\hline Absent & 86 & $40.7 \pm 5.0$ & $35.2(25.9 ; 56.1)$ \\
\hline
\end{tabular}

Mann-Whitney U test: $\mathbf{p}=\mathbf{0 , 0 2}$

In addition, the analysis showed a significantly higher ST2 level in patients with NSTEMI in the presence of acute cardiac arrhythmias (47.1 vs $35.6 \mathrm{ng} / \mathrm{ml}, \mathrm{p}=0.004)$ and acute HF (Killip III) ( $56.3 \mathrm{vs} 35,2 \mathrm{ng} / \mathrm{ml}, \mathrm{p}=0.02$ ) during hospitalization of patients.

Thus, in patients with NSTEMI, a certain association of ST2 level in plasma with the MI course was detected. A higher level of neurohormone is registered with anterior unlike posterior ECG localization of MI; at high unlike moderate risk on the GRACE scale; when complicated unlike the uncomplicated course of MI; in the case of acute HF and cardiac arrhythmias unlike patients with the absence of these manifestations in the acute period of MI.

\section{Discussion}

The results obtained in the course of our study indicated a correlation of ST2 level with different clinical and instrumental characteristics. Thus, an increased level of biomarker was determined in patients with myocardial infarction compared with the control group, which is confirmed by the literature $[15,16]$. The rate was higher in the group of patients with concomitant hypertension, hereditary history, smoking, diabetes and obesity. Most of the literature is centred around STEMI, while ST2 is not well understood in NSTEMI $[9,17]$.

We investigated ST2 levels depending on the localization of myocardial infarction and its complications, which obtained conclusive data regarding the increase of the level of biomarker in the main group compared with the control group.

Given that ST2 levels are correlated with the risk of an unfavourable course of myocardial infarction, its determination in the early stages of the disease allows for appropriate correction of treatment, such as dose modification of drugs or changes in their combinations. If relevant clinical data are available with regard to STEMI, there is very little data regarding NSTEMI [18].

Study limitations. This study examines the therapeutic aspects of the ratio of ST2 levels and the clinical-instrumental characteristics of NSTEMI, while the surgical aspects are 
forced to be neglected. However, the data obtained during the study confirm the indisputable relationship between the level of biomarker and the character of the course of CAD and concomitant HF [19, 20].

Prospects for further research. Of great interest are the associations of ST2 level with the character of the anatomic lesions of the coronary arteries, in particular, the correlative connections according to the SYNTAX score, but we attribute this research to further and prospective studies. The following data will help to optimize the tactics of treating patients in the early period of myocardial infarction immediately after emergency coronary angiography and angioplasty.

\section{Conclusions}

1. High variability of ST2 level in plasma was demonstrated in patients with NSTEMI on the first day after destabilization (minimum and maximum values - 12.7 and 233.9 respectively, median -35.9 and interquartile range -25.9 and $55.7 \mathrm{ng} / \mathrm{ml}$ ).

2. It is shown that significantly higher ST2 level in plasma is determined in patients with acute MI regardless of its variant among different clinical forms of CAD.

3. It is found that significantly higher level of ST2 in patients with NSTEMI is recorded in the case of concomitant HTN and type 2 diabetes, with smoking and heavy cardiovascular heredity. Proved influence of the character of MI course on the level of ST2 in plasma, significantly higher level of neurohormone was determined with anterior localization of MI, high risk on the GRACE scale ( $\geq 140$ points), complicated course of MI, development of cardiac arrhythmias and HF in the acute period of MI.

\section{Conflict of interest}

There is no conflict of interest.

\section{References}

[1] Nichols, M., Townsend, N., Scarborough, P., Rayner, M. (2013). Cardiovascular disease in Europe: epidemiological update. European Heart Journal, 34 (39), 3028-3034. doi: http://doi.org/10.1093/eurheartj/eht356

[2] Kovalenko, V. M., Kornatskiy, V. M.; Kovalenko, V. M., Kornatskiy, V. M. (Eds.) (2014). Circulation system diseases as medical-social and social-politic problem. Kyiv, 279.

[3] Karetnikova, V. N., Kashtalap, V. V., Kosareva, S. N., Barbarash, O. L. (2017). Fibroz miokarda: sovremennye aspekty problemy. Terapevticheskii arhiv, 89 (1), 88-93.

[4] O’Malley, R. G., Bonaca, M. P., Scirica, B. M., Murphy, S. A., Jarolim, P., Sabatine, M. S. et. al. (2014). Prognostic Performance of Multiple Biomarkers in Patients With Non-ST-Segment Elevation Acute Coronary Syndrome. Journal of the American College of Cardiology, 63 (16), 1644-1653. doi: http://doi.org/10.1016/j.jacc.2013.12.034

[5] Piper, S. E., Sherwood, R. A., Amin-Youssef, G. F., Shah, A. M., McDonagh, T. A. (2015). Serial soluble ST2 for the monitoring of pharmacologically optimised chronic stable heart failure. International Journal of Cardiology, 178, 284-291. doi: http:// doi.org/10.1016/j.ijcard.2014.11.097

[6] Gruson, D., Lepoutre, T., Ahn, S. A., Rousseau, M. F. (2014). Increased soluble ST2 is a stronger predictor of long-term cardiovascular death than natriuretic peptides in heart failure patients with reduced ejection fraction. International Journal of Cardiology, 172 (1), e250-e252. doi: http://doi.org/10.1016/j.ijcard.2013.12.101

[7] Bayes-Genis, A., de Antonio, M., Vila, J., Peñafiel, J., Galán, A., Barallat, J. et. al. (2014). Head-to-Head Comparison of 2 Myocardial Fibrosis Biomarkers for Long-Term Heart Failure Risk Stratification. Journal of the American College of Cardiology, 63 (2), 158-166. doi: http://doi.org/10.1016/j.jacc.2013.07.087

[8] Villacorta, H., Maisel, A. S. (2016). Soluble ST2 Testing: Promising Biomarker in the Management of Heart Failure. Arquivos Brasileiros de Cardiologia, 106, 145-152. doi: http://doi.org/10.5935/abc.20150151

[9] Mueller, T., Dieplinger, B. (2013). The Presage ${ }^{\circledR S T} 2$ Assay: analytical considerations and clinical applications for a high-sensitivity assay for measurement of soluble ST2. Expert Review of Molecular Diagnostics, 13 (1), 13-30. doi: http://doi.org/10.1586/ erm.12.128

[10] Bayes-Genis, A., Januzzi, J. L., Gaggin, H. K., de Antonio, M., Motiwala, S. R., Zamora, E. et. al. (2015). ST2 Pathogenetic Profile in Ambulatory Heart Failure Patients. Journal of Cardiac Failure, 21 (4), 355-361. doi: http://doi.org/10.1016/j.cardfail. 2014.10.014 
[11] Lupón, J., Gaggin, H. K., de Antonio, M., Domingo, M., Galán, A., Zamora, E. et. al. (2015). Biomarker-assist score for reverse remodeling prediction in heart failure: The ST2-R2 score. International Journal of Cardiology, 184, 337-343. doi: http:// doi.org/10.1016/j.ijcard.2015.02.019

[12] Gaggin, H. K., Szymonifka, J., Bhardwaj, A., Belcher, A., De Berardinis, B., Motiwala, S. et. al. (2014). Head-to-Head Comparison of Serial Soluble ST2, Growth Differentiation Factor-15, and Highly-Sensitive Troponin T Measurements in Patients With Chronic Heart Failure. JACC: Heart Failure, 2 (1), 65-72. doi: http://doi.org/10.1016/j.jchf.2013.10.005

[13] Vargas, K. G., Kassem, M., Mueller, C., Wojta, J., Huber, K. (2016). Copeptin for the early rule-out of non-ST-elevation myocardial infarction. International Journal of Cardiology, 223, 797-804. doi: http://doi.org/10.1016/j.ijcard.2016.08.304

[14] Raskovalova, T., Twerenbold, R., Collinson, P. O., Keller, T., Bouvaist, H., Folli, C. et. al. (2013). Diagnostic accuracy of combined cardiac troponin and copeptin assessment for early rule-out of myocardial infarction: a systematic review and meta-analysis. European Heart Journal: Acute Cardiovascular Care, 3 (1), 18-27. doi: http://doi.org/10.1177/2048872613514015

[15] Lassus, J., Gayat, E., Mueller, C., Peacock, W. F., Spinar, J., Harjola, V.-P. et. al. (2013). Incremental value of biomarkers to clinical variables for mortality prediction in acutely decompensated heart failure: The Multinational Observational Cohort on Acute Heart Failure (MOCA) study. International Journal of Cardiology, 168 (3), 2186-2194. doi: http://doi.org/10.1016/ j.ijcard.2013.01.228

[16] Maisel, A. S., Richards, A. M., Pascual-Figal, D., Mueller, C. (2015). Serial ST2 Testing in Hospitalized Patients With Acute Heart Failure. The American Journal of Cardiology, 115 (7), 32B-37B. doi: http://doi.org/10.1016/j.amjcard.2015.01.038

[17] Barbarash, O., Gruzdeva, O., Uchasova, E., Dyleva, Y., Belik, E., Akbasheva, O. et. al. (2016). Prognostic Value of Soluble ST2 During Hospitalization for ST-Segment Elevation Myocardial Infarction. Annals of Laboratory Medicine, 36 (4), $313-319$. doi: http://doi.org/10.3343/alm.2016.36.4.313

[18] O’Malley, R. G., Bonaca, M. P., Scirica, B. M., Murphy, S. A., Jarolim, P., Sabatine, M. S. et. al. (2014). Prognostic Performance of Multiple Biomarkers in Patients With Non-ST-Segment Elevation Acute Coronary Syndrome. Journal of the American College of Cardiology, 63 (16), 1644-1653. doi: http://doi.org/10.1016/j.jacc.2013.12.034

[19] Ciccone, M., Cortese, F., Gesualdo, M., Riccardi, R., Di Nunzio, D., Moncelli, M. et. al. (2013). A Novel Cardiac Bio-Marker: ST2: A Review. Molecules, 18 (12), 15314-15328. doi: http://doi.org/10.3390/molecules181215314

[20] Januzzi, J. L., Pascual-Figal, D., Daniels, L. B. (2015). ST2 Testing for Chronic Heart Failure Therapy Monitoring: The International ST2 Consensus Panel. The American Journal of Cardiology, 115 (7), 70B-75B. doi: http://doi.org/10.1016/ j.amjcard.2015.01.044 